Revista de Derecho

\title{
Limitaciones al reconocimiento del territorio ancestral en Ecuador
}

Limitations to the recognition of the ancestral territory in Ecuador

\author{
Andrea Soledad Galindo Lozano \\ Docente de Derecho Constitucional de la Carrera de Derecho \\ Universidad Técnica del Norte, Ecuador \\ asgalindo@utn.edu.ec \\ ORCID: 0000-0001-9562-0517
}

DOI: https://doi.org/10.32719/26312484.2020.34.2

Fecha de recepción: 5 de octubre de 2019

Fecha de aceptación: 9 de enero de 2020

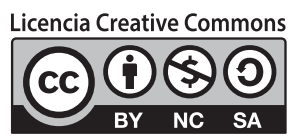




\section{RESUMEN}

A partir de la Constitución de 2008, el Ecuador reconoció el territorio ancestral como un derecho colectivo de las comunidades, pueblos y nacionalidades indígenas por constituir un espacio de preservación de la cultura. Este derecho, que podía considerarse también una manifestación del Estado intercultural, ha sido limitado desde el discurso del Ejecutivo y por medio de disposiciones normativas. La presente investigación aborda el estudio del derecho al territorio ancestral y las limitaciones que este ha sufrido en Ecuador. Para demostrar esta premisa, se analizará uno de los casos emblemáticos sobre los límites al territorio ancestral, se trata de la comunidad Nankints perteneciente al pueblo shuar, sobre la base de dos enfoques: el internacional, a partir de la jurisprudencia de la Corte Interamericana de Derechos Humanos, la Convención Americana de Derechos Humanos y el Convenio 169 de la OIT sobre Pueblos Indígenas y Tribales; y el del Estado intercultural con la revisión de la Constitución ecuatoriana y por las normas que sobre el tema se han expedido. El objetivo de esta investigación es evidenciar que las limitaciones al derecho del territorio ancestral no responden a un análisis teórico-normativo únicamente; en muchas ocasiones son el producto de la voluntad política del gobierno de turno.

PALABRAS ClAVE: interculturalidad, territorio ancestral, derechos de comunidades, pueblos y nacionalidades, derechos colectivos, comunidad Nankints.

\section{ABSTRACT}

As of the 2008 Constitution, Ecuador recognized ancestral territory as a collective right of indigenous communities, peoples and nationalities for constituting a space for the preservation of culture. This right that could also be considered a manifestation of the intercultural state has been limited since the executive's speech and through normative provisions. This research addresses the study of the right to ancestral territory and the limitations it has suffered in Ecuador. To demonstrate this premise, one of the emblematic cases on the boundaries of ancestral territory will be analyzed, it is about the Nankints community belonging to the Shuar people, based on two approaches: the international one, based on the jurisprudence of the Inter-American Court of Human Rights, the American Convention on Human Rights and the ILO Convention 169 on Indigenous and Tribal Peoples; and that of the intercultural State since the revision of the Ecuadorian Constitution through the norms that have been issued on the subject. The objective of this investigation is to show that the limitations to the law of the ancestral territory do not respond to a theoretical-normative analysis only, in many cases they are the product of the political will of the government of the day.

KEYWORDS: interculturality, ancestral territory, rights of communities, peoples and nationalities, collective rights, nankints community. 


\section{INTRODUCCIÓN}

L a interculturalidad, en cuanto eje transversal del ordenamiento jurídico interno e internacional, permite la revalorización e integración de los elementos que siempre fueron parte esencial de la identidad cultural y que durante siglos fueron negados principalmente a los pueblos y nacionalidades. Esta relación de compresión, conocimiento y reconocimiento de todas las culturas resulta en la legitimación social de la espiritualidad y prácticas ancestrales. El territorio ancestral es entendido como un espacio de preservación de la cultura, idioma, usos y costumbres pues es la sustancia de la identidad y autodeterminación de pueblos y nacionalidades, y a partir de la Declaración de las Naciones Unidas sobre Derechos de los Pueblos Indígenas, del convenio 169 sobre Pueblos Indígenas y Tribales de la Organización Internacional del Trabajo (OIT) y de la jurisprudencia de la Corte Interamericana de Derechos Humanos (Corte IDH), se ha convertido en un derecho colectivo y, por tanto, una obligación para los Estados.

Sin embargo, este derecho, que es un desafío importante del Estado intercultural, se encuentra limitado normativa y políticamente. Por un lado, se habla de interculturalidad, de igualdad, equidad y justicia social, pero, por otro, se restringe el acceso a los derechos bajo el discurso del desarrollo y el beneficio de las grandes mayorías. Y, lo que es más grave, la exigencia de las comunidades de este derecho, principalmente ante el Estado ecuatoriano, ha sido calificada como rebelión, terrorismo o sabotaje. Mediáticamente, se ha tratado de privarle de legitimidad al derecho al territorio ancestral pese a tener una protección iusfundamental y supranacional.

Esta investigación plantea el estudio de un caso escogido por el impacto social que produjo en el Estado ecuatoriano desde inicios de 2016 y que continúa hasta hoy. Se trata del Caso Shuar, que inicia con la concesión de un sector de la provincia de Morona Santiago a la empresa China Explorcobres S. A. (Exsa), que comprende parte del territorio ancestral del pueblo indígena shuar de la Amazonía ecuatoriana. La resistencia de este pueblo a las políticas extractivistas llevó al Estado a desconocer derechos colectivos como el territorio ancestral y la consulta previa y a afectar otros como vivienda, educación, salud, alimentación y los derechos de participación por medio de la declaratoria del estado de excepción y la militarización de la comunidad afectada.

Llama la atención que la proclamación de un Estado constitucional y garantista que insiste en la protección de derechos consagrados en la Constitución y en instrumentos de derecho internacional, justifique la afectación de los mismos bajo el discurso político de la explotación minera del territorio ancestral que, como se ha explicado líneas atrás, constituye el nexo espiritual entre la tierra y la identidad de los pueblos y nacionalidades. Tras la promesa de la reinversión en la Amazonía y su desarrollo, se comprometen seriamente los derechos económicos, sociales y culturales de estas minorías. 


\section{EL TERRITORIO ANCESTRAL COMO RECONOCIMIENTO INTERCULTURAL}

La declaración de un Estado intercultural trae consigo la responsabilidad de construir una sociedad que va mucho más allá de la tolerancia y el diálogo, pues su deber es facilitar, en palabras de Walsh, el contacto e intercambio entre culturas en condiciones de igualdad y equidad que procura reforzar las identidades excluidas, ${ }^{1}$ a partir del encuentro mutuo, la convivencia y comprensión de la diferencia. Luis Macas, ${ }^{2}$ por ejemplo, sostiene que la interculturalidad

es parte del reconocimiento de la diversidad desde la pluralidad de culturas, de saberes, pero también desde planteamientos del movimiento indígena como la pluralidad jurídica, educación intercultural bilingüe [...] considera que la interculturalidad es una estrategia del proceso organizativo indígena y debe ser de toda la sociedad. ${ }^{3}$

Pero la interculturalidad no debe ser vista solamente como una práctica de y para los indígenas, pues constituye el espacio de manifestación de las identidades diversas, de sus características y elementos definidores. La interculturalidad implica un aprendizaje y aceptación del ser, hacer y saberes de las diferentes manifestaciones culturales. Por tanto, además de ser una estrategia de todas las culturas, la interculturalidad debe ser una estrategia del Estado.

En consecuencia, el Estado intercultural debe propiciar la transformación estructural de sus instituciones y de la sociedad para potenciar la organización y desarrollo social, espiritual y cultural de un pueblo, sus conocimientos y valores. Es decir, por medio de la percepción del "otro", que implica la interculturalidad, destruir la universalidad y homogeneidad para individualizar y reconceptualizar los elementos que componen cada cultura y, entonces, poder comprender la diferencia, respetarla y generar un espacio de intercambio flexible que nos permita ser todos y no solamente

1. Catherine Walsh, Interculturalidad, Estado, Sociedad. Luchas (de)coloniales de nuestra época (Quito: Abya-Yala, 2009), 35-41.

2. Dirigente indígena de nacionalidad kichwa-saraguro. Expresidente de la CONAIE, exdiputado nacional y exrector de la Universidad Intercultural de las Nacionalidades y Pueblos Indígenas. Para mayor referencia, ver Consejo de Participación Ciudadana y Control Social, Luis Macas Ambuludi (Quito: Consejo de Participación Ciudadana y Control Social), https://www.cpccs.gob.ec/nuestra-institucion/autoridades/ luis-macas-ambuludi/. Fuente consultada 15/01/2020, 15:00.

3. José Luis Bedón, "El pensamiento de Luis Macas: La interculturalidad es una estrategia del proceso organizado", Movimientos indígenas y sociales del Ecuador, 23 de diciembre de 2004, http://www.llacta.org/ organiz/coms/com852.htm. Fuente consultada 22/02/2018, 15:00. 
nosotros y los otros. Esta forma de interculturalidad, definida por Walsh como crítica, debe entenderse, construirse y posicionarse como un:

proyecto político, social, ético y epistémico que se afirma en la necesidad de cambiar no solo las relaciones, sino también las estructuras, condiciones y dispositivos de poder que mantienen la desigualdad, inferiorización, racialización, discriminación, incluyendo con relación a las estructuras jurídicas. ${ }^{4}$

Finalmente, además de reconocer y respetar la comprensión de mundos distintos, la interculturalidad tiene otra connotación cuando se desarrolla en un mismo territorio. Implica reconocer derechos, instituciones y prácticas, pero lejos de la dominación y el poder, de este modo alcanzando su materialización. Un Estado intercultural debe defender el derecho de los grupos culturales a desarrollar su identidad y procurar las condiciones jurídicas y políticas que se requieran para garantizarlo. Este reconocimiento debe obedecer a un enfoque de respeto y comprensión del ejercicio de la libertad de identidad de los grupos étnicos, es decir, el contenido y alcance de los derechos debe provenir de estos sujetos y no únicamente del Estado.

El territorio es el elemento que mantiene una estrecha vinculación con la cultura de un pueblo, es el elemento fundamental para el desarrollo de cualquier tipo de actividad humana. Históricamente, el debate sobre el territorio ha centrado su atención en determinar los límites y alcances de la propiedad del Estado frente a la propiedad privada y la relación existente entre la propiedad privada y el Estado, principalmente desde la lógica de los tributos. El Derecho ha desempeñado un rol protagónico dentro de este proceso, siendo siempre el elemento desde el cual se establecen las reglas para determinar a quién le pertenece el territorio, qué actividades se puede realizar dentro de aquel territorio, los mecanismos de transferencia y su relación con el Estado.

El vértice desde el cual se ha realizado toda esta regulación es el Derecho, visto desde una perspectiva eminentemente normativa y positiva, que no ha logrado incluir dentro de su debate las dimensiones no normativas del territorio, pues es el resultado de complejos procesos de evolución social, dentro de los cuales existe un contexto cultural, histórico y sociológico que moldea la concepción del territorio. Dentro de un Estado constitucional de Derechos y Justicia, no es posible analizar el territorio exclusivamente desde la óptica del texto establecido en las disposiciones normativas,

4. Catherine Walsh, "Interculturalidad crítica y pluralism jurídico" (ponencia, Seminario Pluralismo Jurídico, Procuradora del Estado/Ministerio de Justicia, Brasilia, 13-14 de abril 2010), http://repositorio. uasb.edu.ec/bitstream/10644/6205/1/Walsh\%2C\%20C.-CON-002-Interculturalidad.pdf. Fuente consultada 16/01/2020, 17:00, 6 . 
pues es necesario además considerar su legitimidad y el impacto que causa dentro de la sociedad.

Sobre esta base, es preciso concebir los fundamentos del territorio de una forma integral que va más allá de los lineamientos normativos marcados por la propiedad privada en confrontación con la propiedad pública, pues esta diferenciación bidireccional del territorio se construye como un fenómeno reduccionista, que invisibiliza las múltiples dimensiones del territorio en razón del deber ser de las funciones que cumple y del grupo de personas a quienes les pertenece. Lejos de ser un fenómeno apacible y libre de conflicto, el establecimiento, delimitación y asignación del territorio, es el resultado de una pugna de poder que, de forma general, no tiene como horizonte la garantía de derechos por medio de la asignación del territorio, sino que está dirigida hacia la satisfacción de intereses de carácter económico, a nivel particular y estatal.

Esta corriente integradora exige una determinación del significado del territorio. La CIDH ha identificado la necesidad de forjar una nueva dimensión del territorio, que no representa solamente a la lógica de la propiedad o de la extracción de recursos naturales, sino la de un concepto amplio, particularmente de territorios indígenas que incluye aquellos espacios que son utilizados para sus actividades culturales o de subsistencia. ${ }^{5} \mathrm{Al}$ respecto es preciso hacer un necesario énfasis en que la relación con el territorio no es igual en el mundo indígena y en la tradición occidental. En la cosmovisión indígena, la tierra se constituye como un ente vivo desde el cual se origina la vida y la existencia. Las personas se edifican como parte de la tierra y generan una relación armónica entre el ser humano y la naturaleza en su conjunto. De este modo, el desarrollo comunitario se construye desde la tierra, creándose así vínculos indisolubles de carácter espiritual, cultural y social con el territorio. La perspectiva del territorio en el mundo occidental, por otra parte, está íntimamente ligada a la propiedad privada, en donde no existe una relación profunda con la tierra, sino únicamente el vínculo con un objeto del cual se obtienen recursos, que generalmente ha sido abordado desde el derecho privado o el derecho agrario.

Como lo explica Trujillo, "la tierra es para los pueblos indígenas mucho más que uno de los factores de la producción y, como tal sujeto a las leyes de mercado", 6 ya que es el espacio en el que se desarrollan su cosmovisión y sus prácticas espirituales, de justicia y administrativas. Lejos de estar relacionado con la valoración económica,

5. Comisión IDH, Derechos de los pueblos indigenas y tribales sobre sus tierras ancestrales y recursos naturales. Comisión Interamericana de Derechos Humanos, 2010, https:/www.oas.org/es/cidh/indigenas/ docs/pdf/tierras-ancestrales.esp.pdf. Fuente consultada 15/03/2018, 20:00.

6. Julio César Trujillo, "Derechos colectivos de los pueblos indígenas: conceptos generales", en De la exclusión a la participación: pueblos indígenas y sus derechos colectivos en Ecuador, comp. Angélica Bernal (Quito: Abya-Yala, 2000), 18. 
el espacio físico, tiene una dimensión espiritual pues es vida, en él se desarrolla y es necesario para conservar la existencia de la comunidad y su entorno. El territorio, por tanto, es el eje central de su identidad cultural:

asegurar el derecho al territorio implica aceptar que un pueblo y su cultura están unidos indesligablemente al hábitat donde viven; por ello, el territorio se considera un espacio indivisible que comprende el bosque, sus suelos y los recursos de los cuales los grupos originarios se valen para asegurar su subsistencia y continuidad. ${ }^{7}$

Por lo tanto, el territorio para los pueblos indígenas es aquel punto de partida y de llegada, el vértice desde el cual se genera la vida misma y el destino hacia el cual se dirige toda la actividad humana. Así, el territorio no es únicamente aquel espacio físico en donde se desarrolla la vida del elemento humano, sino que se crean vínculos bidireccionales con la tierra, además de generar un complejo contexto social y cultural de los pueblos indígenas, "si los pueblos indígenas son despojados de sus territorios su derecho a la autoidentificación estaría amenazado, pues este comprende mucho más que un derecho de propiedad". ${ }^{8}$ De este modo, la garantía del derecho al territorio es vital tomando en cuenta el nivel de riesgo de afectación de los derechos de los pueblos indígenas en caso de que se afecte su derecho al territorio ancestral, pues, incluso de acuerdo con el razonamiento realizado por la Corte Interamericana de Derechos Humanos, representa la protección de los derechos humanos de una colectividad que basa su desarrollo económico, social y cultural en la relación con la tierra. ${ }^{9}$

La característica ancestral del territorio debe ser comprendida como aquel derecho a la tierra, asumida como propiedad colectiva, originada desde las luchas y conquistas de los pueblos y comunidades indígenas y edificada desde el desarrollo de múltiples procesos sociales colectivos ligados a la tierra vida. De esta forma, el fin del territorio ancestral se dirige hacia la materialización de los derechos de pueblos y nacionalidades indígenas, dentro de los cuales están incluidos los derechos de la tierra, y al reconocimiento de un conjunto de garantías culturales, sociales y políticas que son inescindibles de los derechos territoriales. Los derechos de propiedad indígena sobre los territorios se extienden sobre todas aquellas tierras y recursos que los pueblos indí-

7. Anahí Durand, ¿Tierra de nadie? Actividad extractiva, territorio y conflicto social en Amazonía peruana: el río Cenepa (Perú: ILC, 2011), 4.

8. Ibíd.

9. Corte IDH, "Sentencia de 17 de junio de 2005”, Caso Comunidad indígena Yakye Axa Vs. Paraguay, 17 de junio de 2005, http://www.corteidh.or.cr/docs/casos/articulos/seriec_125_esp.pdf. Fuente consultada 15/03/2018, 20:00. 
genas usan actualmente, y sobre aquellas tierras y recursos de los que, en otro tiempo, fueron poseedores y de los cuales fueron despojados. ${ }^{10}$

En Ecuador, sobre la base de lo dispuesto por la Constitución y de Tratados y Convenios Internacionales de los cuales el Ecuador es parte, se ha creado la Ley Orgánica de Tierras Rurales y Territorios Ancestrales, que tiene por objeto garantizar la propiedad de tierras comunitarias. En este sentido, por primera vez en la historia del Ecuador se crea una definición de territorio ancestral, definiéndolo de la siguiente forma:

Artículo 3.- Posesión y propiedad ancestral. Para efectos de esta Ley, se entiende por tierra y territorio en posesión y propiedad ancestral, el espacio físico sobre el cual una comunidad, comuna, pueblo o nacionalidad de origen ancestral, ha generado históricamente una identidad a partir de la construcción social, cultural y espiritual, desarrollando actividades económicas y sus propias formas de producción en forma actual e ininterrumpida. La propiedad de estas tierras y territorios es imprescriptible, inalienable, inembargable e indivisible, su adjudicación es gratuita y está exenta del pago de tasas e impuestos. ${ }^{11}$

\section{MORONA SANTIAGO, LA ESTRATEGIA DEL ESTADO FRENTE AL CONFLICTO DE DERECHOS}

En agosto de 2016, antes de dar inicio al proyecto minero San Carlos de Panantza, ${ }^{12}$ militares y policías ecuatorianos desalojaron a 35 familias que habitaban el sector Nankints y Tsuntsuimi, Morona Santiago, pertenecientes al pueblo shuar. El Estado, obligado a realizar la consulta previa, garantizar el territorio ancestral y la reubicación en condiciones adecuadas en el caso de ser inevitable la explotación, invadió su territorio y con violencia expulsó a los habitantes, quienes se refugiaron en las comunidades cercanas de Tiink y Guapis. ${ }^{13}$ En noviembre del mismo año, guerreros del pueblo shuar se tomaron el campamento minero reclamando su territorio ancestral y

10. Comisión IDH, Derechos de los pueblos indígenas y tribales sobre sus tierras ancestrales y recursos naturales.

11. Ecuador, Ley Orgánica de Tierras Rurales y Territorios Ancestrales, Registro Oficial 711, Suplemento, 14 de marzo de 2016, art. 3.

12. Para el desarrollo del proyecto minero San Carlos Panantza el Estado ecuatoriano ha concesionado 41.760 hectáreas a la empresa China Explorcobres S. A. (Exsa). Dentro de este territorio, localizado en el cantón San Juan Bosco, parroquia Santiago de Panantza, provincia de Morona Santiago, se encuentra asentado el pueblo shuar. Para mayor referencia ver, Daniela Aguilar, "Gobierno de Ecuador vs. Pueblo Shuar: un conflicto sin vía de solución”, Mongabay Latam. Periodismo Ambieltal Independiente, 2 de febrero de 2017, https://es.mongabay.com/2017/02/conflictos-pueblos_indigenas-mineria-amazonia-contaminacion/. Fuente consultada el 20/03/2018, 11:00.

13. Susana Morán, “¿El etnocidio del pueblo Shuar?”, Plan V Multimedia, 24 de abril de 2017, http://www. planv.com.ec/historias/sociedad/el-etnocidio-del-pueblo-shuar. Fuente consultada 20/03/2018, 11:00. 
la afectación de derechos de los desplazados. Como resultado de los enfrentamientos un policía murió y varias personas resultaron heridas. Ante estas circunstancias, el presidente de la República, por medio del decreto ejecutivo 1276, declaró el estado de excepción en la provincia de Morona Santiago.

La afectación de los derechos a una vivienda digna, educación, salud, alimentación, cultura y territorio ancestral de las familias desplazadas, que condiciona sus posibilidades de vida y existencia cultural, no fue objeto de análisis en la declaratoria del estado de excepción y, por tanto, las medidas adoptadas por el Estado no estaban dirigidas a garantizar los derechos constitucionales, sino a garantizar el orden interno en la provincia de Morona Santiago por medio de la restricción de algunos derechos y la movilización de la Policía Nacional y las Fuerzas Armadas. ${ }^{14}$

Las casas, el centro de salud y la escuela de Nankints se convirtieron en el campamento de militares y policías. Inició la cacería de los dirigentes de la comunidad, pues la orden presidencial fue encontrar al culpable de la muerte del policía. Trece comuneros fueron encarcelados y posteriormente liberados por no existir pruebas concretas. El gobierno del expresidente Rafael Correa no solamente usaba la privación de libertad como una forma de amedrentar. Recurrió también a la manipulación mediática para fomentar el descontento social, provocando que la resistencia del pueblo shuar y la defensa de su territorio ancestral fueran vistas como rebelión y terrorismo, pues públicamente se los catalogó como grupos ilegalmente armados.

La oposición del pueblo shuar a la concesión de explotación de minerales otorgada a la empresa china en el extenso territorio ubicado en Morona Santiago, por incluir al espacio considerado como ancestral, rápidamente se transformó en una grave afectación a la función social que deben cumplir la propiedad, los bienes públicos y la propiedad privada, pues es necesario aclarar que dicha empresa posee un título de dominio sobre el territorio en cuestión.

Durante el enlace ciudadano ${ }^{15}$ realizado el 19 de diciembre de 2016, el expresidente Correa enfatizó que durante varios años siete familias que ahora se denominan comunidad de Nankints constantemente han invadido ese territorio y que en varias ocasiones fueron expulsados, existiendo incluso una orden judicial para su desalojo. Manifestó también que:

14. Ecuador, Decreto Ejecutivo 1276, 14 de diciembre de 2016, https://www.eltelegrafo.com.ec/images/cms/ politica/2016/Diciembre/14-12-16/estadoexcepcionmorona.pdf. Fuente consultada 20/03/2018, 11:00.

15. Espacio informativo que se implementó durante el gobierno de Rafael Correa cada sábado en distintos lugares dentro del territorio nacional. 
si se oponen es solo porque no quieren que haya minería, no porque son ancestrales. Que ganen las elecciones si quieren ser gobierno e impedir la minería [...] pero por ancestrales que sean, mientras yo sea presidente todos vamos a estar sometidos al estado de derecho, todos vamos a respetar la propiedad pública y privada. ${ }^{16}$

Posteriormente los titulares de la prensa informaban: Caso Shuar: violencia interna daña la democracia en Ecuador, ${ }^{17}$ El presidente Rafael Correa citó un video que revela el modus operandi de un grupo de violentos que se ampara en "derechos ancestrales", ${ }^{18}$ Policía murió en el ataque al campamento minero, ${ }^{19}$ etc. El objetivo de deslegitimar socialmente a pueblos y nacionalidades empezó a realizarse por medio de la alarma social y la estigmatización de la protesta y la resistencia.

La posición política de Perú, por ejemplo, frente a la explotación de recursos naturales no renovables siempre ha sido clara. Alan García, expresidente de Perú, ha manifestado que existen "millones de hectáreas ociosas para maderas porque las comunidades no cultivaron ni cultivarán nada, depósitos minerales que no se trabajan, petróleo en el subsuelo desperdiciado". ${ }^{20}$ No sorprende, entonces, el desconocimiento de los derechos del pueblo originario awajum, de acuerdo con el informe de Durand. ${ }^{21}$ Sin embargo, la posición política del Gobierno ecuatoriano respecto de la explotación de recursos no renovables es confusa. En el año 2011, por ejemplo, el expresidente Correa respaldó la postura de las comunidades de la Amazonía frente al caso Chevron al defender su territorio ante los desastres de la explotación petrolera. ${ }^{22}$ Las acusaciones de la transnacional en contra del Gobierno, los daños ambientales y la negativa de Chevron de asumir la responsabilidad sobre la contaminación, muerte y afectación de

16. Para mayor referencia ver, Ecuador Transparente, "Correa dice que la comunidad Nankints es un invento", 19 de diciembre de 2016, a partir del enlace ciudadano con el expresidente del Ecuador Rafael Correa, https://www.youtube.com/watch?v=M8kvUBCHdD4. Fuente consultada 15/01/2020, 15:00.

17. Consejo de Gobierno del pueblo Shuar Arutam, "Caso Shuar: Violencia daña democracia en Ecuador", Servicios de comunicación intercultural SERVINDI, Boletín de prensa n. ${ }^{\circ}$ 2-20170124 del 26 de enero de 2017 , https://www.servindi.org/actualidad-noticias/26/01/2017/estos-hechos-de-violencia-interna-son-el-indiciodel-detrimento-la. Fuente consultada 11/09/2017 13:00.

18. TeleSUR, "Video revela modus operandi de extorsión a los shuar en Ecuador", La nueva televisión del Sur C.A., 24 de diciembre de 2016, https:/www.telesurtv.net/news/Video-revela-modus-operandi-de-extorsiona-los-shuar-en-Ecuador-20161224-0017.html. Fuente consultada 12/09/2017 10:00.

19. El Telégrafo, "Policía murió en ataque a campamento minero", 15 de diciembre de 2016, https:/www. eltelegrafo.com.ec/noticias/politica/2/policia-murio-en-ataque-a-campamento-minero. Fuente consultada 12/09/2017 10:00.

20. Durand, ¿Tierra de nadie?, 1.

21. Ibíd.

22. TeleSUR, "Correa felicita a indígenas de la Amazonía por 'hacer historia' en caso contra Chevron”, video de YouTube, 19 de febrero de 2011, https:/www.youtube.com/watch?v=VFdso-1LbgM. Fuente consultada 15/01/2020, 15:00. 
los derechos de las comunidades indígenas y colonos de la Amazonía ecuatoriana, dio origen a la campaña internacional impulsada por el Gobierno ecuatoriano "la mano sucia de Chevron". ${ }^{23}$ Unos años después, en el caso que se analiza, la reacción de gobierno ecuatoriano es totalmente contraria, debido a que se parte de dos elementos: la protección de la propiedad privada de una transnacional de la República Popular de China, Estado que se ha convertido en socio estratégico del Ecuador, y la protección del territorio de una comunidad formada por "siete familias" que se dice ancestral y que se opone a la minería y por tanto al desarrollo.

Lógicamente una minoría étnica no tiene representación alguna frente al Estado, por el contrario, constituye un problema para el modelo económico, además, no se trata de un bien público, existe un legítimo propietario. Por tanto, la protesta por la protección de los derechos de la comunidad de Nankints debe ser neutralizada porque no es funcional al orden nacional y desafía a las instituciones del Estado y al modelo económico impuesto, es decir la explotación de recursos que trae consigo el desarrollo de los pueblos. En palabras de Walsh,

el reconocimiento y respeto a la diversidad cultural se convierten en una nueva estrategia de dominación, la que apunta al control del conflicto étnico-racial y la conservación de la estabilidad social con el fin de impulsar los imperativos económicos del modelo (neoliberalizado) de acumulación capitalista. ${ }^{24}$

La Corte Interamericana de Derechos Humanos en varios casos ha declarado que tanto la propiedad privada de los particulares como el territorio ancestral de las comunidades tiene una igual protección. Al afectar el derecho a la propiedad privada como a la ancestral, se puede desconocer otros derechos básicos como salud, vivienda, alimentación, trabajo, etc. No obstante, si se desconoce el derecho al territorio ancestral se afecta, además, el derecho a la identidad cultural y el de la existencia de la misma comunidad. Consecuentemente, de ser necesario, dice la Corte, se podrá restringir el derecho a la propiedad privada, luego de cancelar el justo precio por la misma, para preservar las identidades culturales. ${ }^{25}$

23. Ecuador, Ministerio de Relaciones Exteriores y Movilidad Humana, El caso Chevron/Texaco en Ecuador. Una lucha por la justicia ambiental y social (Quito: Ministerio de Relaciones Exteriores y Movilidad Humana), https://www.cancilleria.gob.ec/wp-content/uploads/2015/06/Expediente-Caso-Chevronabril-2015.pdf. Fuente consultada 15/01/2020, 15:00. Ver https://www.youtube.com/watch?v=_Ip51_ doa8w. Fuente consultada 15/01/2020, 15:00.

24. Walsh, Interculturalidad crítica y pluralismo jurídico, 7.

25. Corte IDH, "Sentencia de 17 de junio de 2005", Caso Comunidad indígena Yakye Axa Vs. Paraguay, 17 de junio de 2005. 
Adicionalmente la Corte Interamericana de Derechos Humanos, en la interpretación evolutiva efectuada al art. 21 de la Convención Americana de Derechos $\mathrm{Hu}$ manos a la luz del Convenio 169 de la OIT, había indicado en el caso Sarayaku vs. Ecuador, que el Estado tiene la obligación de consultar a los pueblos y nacionalidades para realizar la exploración y explotación de recursos naturales en propiedad comunitaria. ${ }^{26}$ Este aspecto tampoco fue observado al emitir el Decreto Ejecutivo 1276.

Si bien no es objeto de esta investigación la procedencia de la declaratoria de estado de excepción, es importante precisar que el Decreto Ejecutivo 1276 no obedeció a los parámetros establecidos en el artículo 164 de la Constitución ecuatoriana, principalmente a la necesidad y proporcionalidad. Las disposiciones normativas internas e internacionales relativas al territorio ancestral son claras: el Estado debía garantizar el derecho al territorio ancestral por la posible afectación a otros derechos básicos y los de identidad y existencia cultural y, por tanto, declarar la expropiación del espacio territorial considerado como ancestral para que la comunidad pueda vivir libremente en su propio territorio. Y solamente ante la imposibilidad de la expropiación y con el consentimiento de la comunidad debía reubicarla en un espacio que guardara las mismas características, principalmente el vínculo espiritual de los pobladores con la tierra. $^{27}$

El estado de excepción emitido por el expresidente Correa definitivamente no fue necesario pues existía, como se ha explicado en el párrafo anterior, un mecanismo más adecuado para resolver el conflicto. Tampoco cumplió el parámetro de proporcionalidad, debido a que la expulsión del territorio y la militarización de la comunidad, agudizaron la afectación de los derechos de educación, salud, vivienda, trabajo e identidad, incluso de niños, niñas, adolescentes y ancianos. Así mismo, se comprometió la vida y la salud de dos mujeres que entraron en labor de parto mientras huían a causa de los disparos de los militares, según narra Claudia Chumpi. ${ }^{28}$

La estrategia empleada por el Estado ecuatoriano, que se ha convertido en una reacción habitual ante la protesta social principalmente cuando se trata de exploración y explotación de minerales, no solo afecta derechos constitucionales, sino que además persigue y silencia las voces de los excluidos. Por medio del discurso del desarrollo y una minería responsable, el expresidente calificó y descalificó la ancestralidad de un territorio, la violación de derechos, la justicia social, la interculturalidad, la paz e

26. Corte IDH, "Sentencia de 27 de junio de 2012", Caso Pueblo Indígena Kichwa de Sarayaku Vs. Ecuador, 27 de junio de 2012.

27. Organización Internacional del Trabajo, Convenio 169 sobre Pueblos Indígenas y Tribales, 5 de septiembre de 1991, art. 16, http://www.ilo.org/dyn/normlex/es/f?p=NORMLEXPUB:12100:0::NO::P12100_INSTRUMENT_ID:312314. Fuente consultada el 14/03/2018, 17:00.

28. Aguilar, "Gobierno de Ecuador vs. Pueblo Shuar: un conflicto sin vía de solución". 
igualdad. Es un discurso que únicamente ha vaciado de contenido los valores y principios establecidos por el constituyente y ratificados por todos los ecuatorianos.

\section{LIMITACIONES AL RECONOCIMIENTO DEL TERRITORIO ANCESTRAL}

El derecho al territorio ancestral consagrado en el artículo 57 de la Constitución ecuatoriana fue reconocido ampliamente y sin limitaciones ${ }^{29}$ de forma casi idéntica a la declaración realizada por el Convenio 169 de la OIT. ${ }^{30}$ Es decir, no existe una restricción iusfundamental a este derecho, lo que no sucede con el derecho a la propiedad privada que se encuentra condicionada por la función social y ambiental. ${ }^{31}$

No obstante, el inciso cuarto del art. 100 de la Ley Orgánica de Tierras Rurales y Territorios Ancestrales incorpora la obligación para los territorios ancestrales de cumplir con la función social y la función ambiental, aunque no serán sujetos de afectación o expropiación agraria. Esta norma indica también el procedimiento que deberá seguirse para la delimitación y adjudicación de estos territorios, así como los derechos correlativos a la propiedad ancestral. Así mismo, define la posesión ancestral como la ocupación actual e inmemorial del territorio donde se reproduce la identidad de un pueblo y aclara que ocupación inmemorial es la permanencia en un espacio territorial. ${ }^{32}$

El 11 de enero de 2017, luego de los incidentes suscitados en el Caso Shuar y otros más, la Asamblea Nacional crea el Reglamento a la Ley Orgánica de Tierras Rurales y Territorios Ancestrales. El art. 1 de este instrumento, que contiene las definiciones, señala que la ocupación inmemorial de un territorio es la posesión ancestral por 50 años o más. Luego, en el art. 5 y siguientes establece los parámetros generales y específicos de la función social y la función ambiental que deberán cumplir los predios, sin aclarar si se refiere únicamente a las tierras rurales o también a los territorios ancestrales. ${ }^{33}$

Convenientemente, en un reglamento se establece un requisito temporal para el ejercicio de un derecho contenido en la norma suprema y en instrumentos internacionales de derechos humanos de aplicación directa e inmediata en el ordenamiento jurídico ecuatoriano. Lo que sorprende aún más es que dicho reglamento dedica de forma

29. Ecuador, Constitución de la República del Ecuador, art. 57 num. 4, 5 y 11. Registro Oficial 449, 20 de octubre de 2008.

30. Organización Internacional del Trabajo, Convenio 169 sobre Pueblos Indigenas y Tribales, arts. 13-9.

31. Ecuador, Constitución de la República del Ecuador, art. 66 num. 26.

32. Ecuador, Ley Orgánica de Tierras Rurales y Territorios Ancestrales, arts. 77-100.

33. Ecuador, Reglamento a la Ley Orgánica de Tierras Rurales y Territorios Ancestrales, arts. 1-5, Registro Oficial 920, Suplemento, 11 de enero de 2017. 
exclusiva dos artículos al territorio ancestral pues está dirigido casi en su totalidad a las tierras rurales.

Ahora bien, la Corte Interamericana de Derechos humanos, en el caso de la Comunidad indígena de Yakye Axa vs. Paraguay, estableció las pautas que deberán tomar en cuenta los Estados cuando se produzcan conflictos entre la propiedad privada y el territorio ancestral, límites que se describen a continuación:

a) El reconocimiento de las tierras ancestrales carece de sentido si antes no se ha delimitado físicamente la propiedad.

b) Deben estar establecidos por ley. Por medio de la ley se puede subordinar el uso y goce de la propiedad al interés social.

c) Deben ser necesarios, es decir cuando la medida, suficientemente motivada, está dirigida a satisfacer un interés público imperativo.

d) Deben ser proporcionales, cuando la medida está orientada al cumplimiento de un objetivo, afectando lo menos posible al ejercicio del derecho.

e) Deben realizarse para lograr un objetivo legítimo en una sociedad democrática, el objetivo es legítimo cuando es colectivo y está investido de tal trascendencia que se ubica por encima de derecho restringido. ${ }^{34}$

$\mathrm{Al}$ aplicar estas pautas establecidas por la Corte, lo más probable es que si surge un conflicto entre la propiedad pública y la ancestral se prefiera esta última, básicamente porque al limitar el derecho al territorio ancestral podría afectarse más derecho, la mayoría de ellos de carácter colectivo. Esto, desde luego, obedece al estudio de caso concreto como lo ha recomendado también la Corte, ${ }^{35}$ ya que como se señaló anteriormente, ante la imposibilidad del Estado de proteger el derecho al territorio ancestral, deben adoptarse medidas que no descuiden el significado de las tierras para la comunidad.

Lo que aparentemente estaría suficientemente claro tiene otra particularidad: ¿quién tiene la titularidad sobre el uso y goce de los recursos naturales que se encuentren en tierras ancestrales? Este aspecto es abordado por la Corte Interamericana de Derechos Humanos en el caso Saramaka vs. Surinam. La Corte, luego de analizar que el art. 21 de la Convención Americana de Derechos Humanos, indica que este no puede entenderse como absoluto pues el territorio ancestral debe también tener sus limitaciones. ${ }^{36}$

34. Corte IDH, "Sentencia de 17 de junio de 2005", Caso Comunidad indígena Yakye Axa vs. Paraguay, 17 de junio de 2005 .

35. Ibíd.

36. Corte IDH, "Sentencia de 28 de noviembre de 2007", Caso del Pueblo Saramaka vs. Surinam. 28 de noviembre de 2007. 
El territorio ancestral, como se ha explicado, es el espacio que permite el desarrollo pleno de una cultura y proporciona todos los medios para la existencia e identidad de esta, así como también para la ejecución de sus actividades económicas y productivas propias. El uso y goce de los recursos naturales, por tanto, permite el mantenimiento del estilo de vida de la comunidad y la continuidad de la vida. Sin embargo, el subsuelo y los recursos renovables y no renovables que se encuentran dentro de él, son propiedad exclusiva del Estado. La Corte ha indicado que el otorgamiento de concesiones para la exploración y explotación de minerales por parte del Estado, por un lado, debe constituir una limitación al derecho al territorio ancestral. Pero, por otro, estas actividades, que en la mayoría de los casos son invasivas, podían producir una alteración importante del entorno y consecuentemente del modo de vida de los pueblos. ${ }^{37}$

Ante la posible afectación de los derechos constitucionales y la calidad de vida de estos pueblos, la Corte ha previsto tres garantías para que la exploración y explotación de recursos no impliquen la denegación de la subsistencia de la comunidad:

a) El Estado debe asegurar la participación, de la comunidad afectada, en la creación del plan de desarrollo, inversión y explotación de recursos.

b) El Estado debe garantizar que la comunidad afectada se beneficie del proyecto extractivo.

c) No se autorizará ninguna concesión mientras no se haya realizado los correspondientes estudios técnicos del impacto social y ambiental. ${ }^{38}$

Pese a que las normas internacionales e internas no contemplan directamente la posibilidad de establecer límites al territorio ancestral, la Corte Interamericana de Derechos Humanos ha establecido pautas claras para resolver los posibles conflictos de derechos que puedan originarse al entrar en confrontación la propiedad privada y el territorio ancestral y este último con la titularidad exclusiva del Estado de los recursos renovables y no renovables que reposan en el subsuelo del territorio nacional.

En el caso objeto de esta investigación, es posible verificar el incumplimiento del Estado ecuatoriano no solamente de los instrumentos internacionales y la inobservancia de las disposiciones complementarias establecidas jurisprudencialmente, sino también evidenciar la distorsión de la Norma Suprema a partir de un reglamento, políticas públicas, persecución mediática y deslegitimación social.

El Estado ecuatoriano desconoció públicamente el derecho al territorio ancestral del pueblo shuar, protegiendo la propiedad privada de la trasnacional china. Para legitimar esta postura se restringe este derecho con un requisito temporal que reposa en

37. Corte IDH, "Sentencia de 28 de noviembre de 2007", Caso del Pueblo Saramaka vs. Surinam.

38. Ibíd. 
un instrumento infralegal que debió ser declarado inconstitucional. Sin consultar a la comunidad concesionó el proyecto de exploración y explotación de minerales, el que evidentemente fue desarrollado sin la participación del pueblo shuar como directo afectado por el proyecto, y sin un estudio previo de impacto social, instrumento que pudo prever la afectación actual del derecho a la salud, educación, vivienda, alimentación, trabajo, identidad y existencia culturales. Finalmente, ante esta imposibilidad de expropiar el territorio debió realizar la reubicación de las familias que fueron desalojadas en un espacio en el que se genere nuevamente esa conexión espiritual de la comunidad con la tierra, decisión que debió ser consensuada con la comunidad.

El Estado constitucional de derechos y justicia que incorpora la interculturalidad como eje trasversal en el ordenamiento jurídico, los derechos colectivos contenidos en instrumentos internacionales de derechos humanos y que consagra a la resistencia como una garantía social y derechos de participación ciudadana, resuelve los conflictos entre derechos mediante medidas políticas y no por medio de disposiciones jurídicas internas e internacionales. La voluntad del Ejecutivo se sitúa de esta manera por encima de la Constitución.

\section{CONCLUSIONES}

Existe la pretensión de que, por ser el Ecuador un país diverso, la interculturalidad debe ser asumida como un hecho natural y el resultado de ella será el reconocimiento y ejercicio pleno de derechos individuales y colectivos. Pero no se trata únicamente de dirigir el ordenamiento jurídico para proclamar derechos porque incluso este reconocimiento y su ejercicio se realizarán desde una condición de inferioridad o de tolerancia. Es decir, el reconocimiento de derechos está condicionado a la existencia del indio permitido, quien, en palabras de Rodríguez, es "el sujeto que está aprobado y validado por el gobierno, por las transnacionales, por los organismos internacionales [...] es el que de manera velada y generalmente de forma irreflexiva, deja de ser sujeto histórico para sumarse a las políticas culturales del Estado". ${ }^{39}$ El caso de la comunidad Nankints perteneciente al pueblo shuar es muestra de ello y de los mecanismos de solución de conflictos de derechos que adopta el Estado cuando podrían verse comprometidos intereses políticos y económicos.

La inobservancia de un ordenamiento jurídico que aparentemente ha logrado coherencia y plenitud -pues las ausencias normativas fueron desarrolladas mediante las

39. Lidia Rodríguez, "El indio permitido en el estado multicultural. Patrimonio, cultura y etnofagia en la tardomodernidad”, Boletín de Antropología Americana n. ${ }^{\circ} 47$ (enero 2011-diciembre 2012), 155. 
disposiciones de organismos de justicia internacionales-, sugiere una pregunta que parece incoherente pero que luego de esta breve investigación es necesario plantear: ¿Se podría contemplar la posibilidad de que la ausencia de límites normativos de un derecho es la puerta abierta para restringirlo políticamente?

La respuesta es clara: el derecho al territorio ancestral debería tener, como todos los derechos, un límite constitucional a su pleno ejercicio, pues el deber de la norma constitucional es establecer la restricción al contenido esencial de los derechos y, en el caso de existir una laguna al respecto, le corresponde al juez constitucional resolver esa ausencia. La Corte Interamericana de Derechos Humanos en varias ocasiones ha manifestado cuál es el contenido esencial del derecho al territorio ancestral, las necesarias restricciones que podrían darse y la forma de garantizar este derecho a pesar de su limitación. Por esta razón, bajo ningún argumento es admisible que, aunque la Constitución ecuatoriana y los instrumentos internacionales de derechos humanos reconocen el derecho al territorio ancestral sin limitación alguna, la ancestralidad se haya convertido en una categoría que se alcanza luego de dar cumplimiento a disposiciones reglamentarias.

Normas que se emiten exclusivamente para un caso, persecución y criminalización de la protesta social; manipulación de la información y descalificación de minorías étnicas, así como la implementación de agresivas políticas extractivistas que se justifican en el discurso del desarrollo, sacrificando la identidad cultural y la existencia de las minorías, son el resultado de un desarrollo más político y menos normativo de un derecho.

\section{BIBLIOGRAFÍA}

Aguilar, Daniela. "Gobierno de Ecuador vs. Pueblo Shuar: un conflicto sin vía de solución". Mongabay Latam. Periodismo Ambiental Independiente. 2 de febrero de 2017. https:// es.mongabay.com/2017/02/conflictos-pueblos_indigenas-mineria-amazonia-contaminacion/. Fuente consultada el 14/03/2018, 17:00.

Ayala Mora, Enrique. Interculturalidad en el Ecuador. http://www.uasb.edu.ec/UserFiles/380/ File/Interculturalidad\%20en\%20el\%20Ecuador.pdf.

Bedón, José Luis. "El pensamiento de Luis Macas: La interculturalidad es una estrategia del proceso organizado". Movimientos indígenas y sociales del Ecuador. 23 de diciembre de 2004. http://www.llacta.org/organiz/coms/com852.htm. Fuente consultada 22/02/2018, 15:00.

Bernal, Angélica. De la exclusión a la participación: pueblos indígenas y sus derechos colectivos en Ecuador. Quito: Abya-Yala, 2000. 
Comisión IDH. Derechos de los pueblos indigenas y tribales sobre sus tierras ancestrales y recursos naturales. Comisión Interamericana de Derechos Humanos. 2010. https:/www.oas.org/es/ cidh/indigenas/docs/pdf/tierras-ancestrales.esp.pdf. Fuente consultada 15/03/2018, 20:00.

Consejo de Gobierno del pueblo Shuar Arutam. "Caso Shuar: Violencia daña democracia en Ecuador". Servicios de comunicación intercultural SERVINDI. Boletín de prensa n. ${ }^{\circ} 2-20170124$ del 26 de enero de 2017. https://www.servindi.org/actualidad-noticias/26/01/2017/estos-hechos-de-violencia-interna-son-el-indicio-del-detrimento-la. Fuente consultada 11/09/2017, 13:00.

Correas, Oscar. La Sociología Jurídica. Un ensayo de definición. https://revistas-colaboracion. juridicas.unam.mx/index.php/critica-juridica/article/viewFile/3076/2876. Fuente consultada el 16/06/2018, 15:00.

Corte IDH, "Sentencia de 17 de junio de 2005". Caso Comunidad indígena Yakye Axa Vs. Paraguay. 17 de junio de 2005. http://www.corteidh.or.cr/docs/casos/articulos/seriec_125_ esp.pdf. Fuente consultada 15/03/2018, 20:00.

—. "Sentencia de 28 de noviembre de 2007". Caso del Pueblo Saramaka vs. Surinam. 28 de noviembre de 2007.

—. "Sentencia de 27 de junio de 2012”. Caso Pueblo Indígena Kichwa de Sarayaku vs. Ecuador. 27 de junio de 2012.

Cruz, Edwin. Pensar la interculturalidad. Una invitación desde Abya-Yala/América Latina. Quito: Abya-Yala, 2013.

Durand, Anahí. ¿Tierra de nadie? Actividad extractiva, territorio y conflicto social en Amazonía peruana: el río Cenepa. Perú: ILC, 2011.

Dussel, Enrique. Transmodernidad e interculturalidad. Interpretación desde la Filosofía de la liberación. http://red.pucp.edu.pe/wp-content/uploads/biblioteca/090514.pdf. Fuente consultada en 16/06/2018, 15:00.

Ecuador. Consejo de Participación Ciudadana y Control Social. Luis Macas Ambuludi. Quito: Consejo de Participación Ciudadana y Control Social. https://www.cpccs.gob.ec/nuestrainstitucion/autoridades/luis-macas-ambuludi/. Fuente consultada 15/01/2020, 15:00.

-. Constitución de la República del Ecuador. Registro Oficial 449, 20 de octubre de 2008.

- Decreto ejecutivo 1276. 14 de diciembre de 2016. https://www.eltelegrafo.com.ec/images/ cms/politica/2016/Diciembre/14-12-16/estadoexcepcionmorona.pdf. Fuente consultada 20/03/2018, 11:00.

- Ley Orgánica de Tierras Rurales y Territorios Ancestrales. Registro Oficial 711, Suplemento, 14 de marzo de 2016.

- Ministerio de Relaciones Exteriores y Movilidad Humana. El caso Chevron/Texaco en Ecuador. Una lucha por la justicia ambiental y social. Quito: Ministerio de Relaciones Exteriores y Movilidad Humana. https://www.cancilleria.gob.ec/wp-content/uploads/2015/06/ExpedienteCaso-Chevron-abril-2015.pdf. Fuente consultada 15/01/2020, 15:00. Ver https://www.youtube. com/watch?v=_Ip51_doa8w. Fuente consultada 15/01/2020, 15:00. 
- Reglamento a la Ley Orgánica de Tierras Rurales y Territorios Ancestrales. Registro Oficial 920, Suplemento, 11 de enero de 2017.

Ecuador Transparente. "Correa dice que la comunidad Nankints es un invento". 19 de diciembre de 2016, a partir del enlace ciudadano con el expresidente del Ecuador Rafael Correa. https:// www.youtube.com/watch?v=M8kvUBCHdD4. Fuente consultada 15/01/2020, 15:00.

El Telégrafo. "Policía murió en ataque a campamento minero". 15 de diciembre de 2016. https://www.eltelegrafo.com.ec/noticias/politica/2/policia-murio-en-ataque-a-campamento-minero. Fuente consultada 12/09/2017, 10:00.

Estermann, Josep. Filosofía Andina. Estudio intercultural de la sabiduría autóctona andina. Quito: Abya-Yala, 1998.

Fundación Tierra. Informe 2010 Territorios Indígena Originario Campesinos en Bolivia. Entre la Loma Santa y la Pachamama. La Paz: Fundación Tierra, 2011.

Garcés, Fernando. "De la interculturalidad como armónica relación de diversos a una interculturalidad politizada”. En Interculturalidad crítica y descolonización. Fundamentos para el debate, dirigido por David Mora. Bolivia: Instituto Internacional de Integración del Convenio Andrés Bello, 2009.

Gómez, Herinaldy, y Cristóbal Gnecco. Representaciones legales de la alteridad indígena. Colombia: Universidad del Cauca, 2008.

Guerrero, Patricio. Corazonar desde las sabidurías insurgentes el sentido de las epistemologias dominantes, para construir sentidos otros de la existencia. https://dialnet.unirioja.es/ servlet/articulo?codigo=5973023. Fuente consultada 22/07/2018, 22:00.

- Reflexiones sobre interculturalidad. Quito: Abya-Yala, 1999.

Huber, Rudolf, Juan Carlos Martínez, Cécile Lachenal y Rosembert Ariza. Hacia sistemas jurídicos plurales. Reflexiones y experiencias de coordinación entre el derecho estatal y el derecho indígena. Bogotá: Konrad-Adenauer-Stiftung, 2008.

Martínez, Ana Teresa. "Pluralismo jurídico y diversidad cultural. Hacia un replanteamiento del concepto de derecho (Reflexiones filosóficas desde las rondas campesinas)". En Juan Abugattás, José Ballón, Augusto Castro y Ana Martínez, Filosofía y Sociedad. Cusco: Centro de Estudios Regionales Andinos Bartolomé de las Casas, 1995.

Mora, David. Interculturalidad crítica y descolonización. Bolivia: Instituto Internacional de Integración del Convenio Andrés Bello, 2009.

Morán, Susana. “¿El etnocidio del pueblo Shuar?”. Plan V Multimedia. 24 de abril de 2017. http://www.planv.com.ec/historias/sociedad/el-etnocidio-del-pueblo-shuar. Fuente consultada 20/03/2018, 11:00.

Organización Internacional del Trabajo. Convenio 169 sobre Pueblos Indígenas y Tribales. 5 de septiembre de 1991. Art. 16. http://www.ilo.org/dyn/normlex/es/f?p=NORMLEXPUB:1210 0:0::NO::P12100_INSTRUMENT_ID:312314. Fuente consultada 14/03/2018, 17:00.

Rodríguez, Lidia. "El indio permitido en el estado multicultural. Patrimonio, cultura y etnofagia en la tardomodernidad". Boletín de Antropología Americana, n. 47 (enero 2011-diciembre 2012). 
Santos, Boaventura de Sousa. Una epistemología del Sur. Ciudad de México: CLACSO, 2014.

TeleSUR. "Correa felicita a indígenas de la Amazonía por 'hacer historia' en caso contra Chevron". Video de YouTube. 19 de febrero de 2011. https://www.youtube.com/ watch?v=VFdso-1LbgM. Fuente consultada 15/01/2020, 15:00.

- . "Video revela modus operandi de extorsión a los shuar en Ecuador". La nueva televisión del Sur C.A. 24 de diciembre de 2016. https://www.telesurtv.net/news/Video-revela-modus-operandi-de-extorsion-a-los-shuar-en-Ecuador-20161224-0017.html. Fuente consultada 12/09/2017, 10:00.

Trujillo, Julio César. "Derechos colectivos de los pueblos indígenas: conceptos generales". En De la exclusión a la participación. Pueblos indígenas y sus derechos colectivos en el Ecuador, compilado por Angélica Bernal. Quito: Abya-Yala, 2000.

Viaña, Jorge. La interculturalidad como herramienta de emancipación. Bolivia: Instituto Internacional de Integración del Convenio Andrés Bello, 2009.

Walsh, Catherine. "Interculturalidad crítica y pluralism jurídico". Ponencia presentada en el Seminario Pluralismo Jurídico, Procuradora del Estado/Ministerio de Justicia, Brasilia, 1314 de abril 2010. http://repositorio.uasb.edu.ec/bitstream/10644/6205/1/Walsh\%2C\%20 C.-CON-002-Interculturalidad.pdf.

-. Interculturalidad, Estado, sociedad. Luchas (de)coloniales de nuestra época. Quito: AbyaYala, 2009.

Wolkmer, Antonio Carlos. Pluralismo jurídico. Fundamentos de una nueva cultura del Derecho, 2. ${ }^{a}$ ed. Madrid: Dykinson, 2018. 